\title{
Envejecimiento y deterioro de las personas con discapacidad intelectual de Lantegi Batuak en el ámbito ocupacional y del empleo en Bizkaia.
}

\section{Lantegi Batuak \\ <info@lantegi.com>}

Edurne Elorriaga Zugazaga

\section{William Restrepo}

Lantegi Batuak

\section{Víctor Bayarri}

Lantegi Batuak

\section{Yolanda Fillat}

Alter Civites
Artikulu honetan biltzen dira Lantegi Batuak erakundeak Bizkaiko lanbide terapia eta enpleguaren arloan ikasteko urritasunak dituzten pertsonen zahartze eta andeatzeren inguruan egindako ikerketa eta gogoetarako proiektu baten ondorioak. Proiektu horren helbururako xedea izan da ikasteko urritasuna izan eta laneko ingurunean zahartzen diren pertsona horien partaidetza eta autonomia errazteko ekimenak prestatzea. Horren bidez prebenitu nahi da lanpostuen galera, berauen bizimailaren okertzea eta diskriminatzeak gertatzeko arriskua. Horretaz gain, sustatu nahi dira pertsona horiek lan egiten duten enplegu berezietarako zentroak eta lanbidearen terapiaren arloko zerbitzuak.

\section{HITZ-GAKOAK:}

zahartzea, andeatzea, enplegua, ikasteko ezintasuna, lanbide terapia.
Este artículo sintetiza los resultados de un proyecto de investigación y reflexión de Lantegi Batuak en torno al envejecimiento y el deterioro de las personas con discapacidad intelectual en el ámbito ocupacional y de empleo de Bizkaia. La finalidad de dicho proyecto era diseñar nuevas acciones que facilitaran una mayor participación y autonomía de las personas con discapacidad intelectual que envejecen en el ámbito laboral. Con ello se buscaba prevenir la pérdida de puestos de trabajo, el deterioro de su calidad de vida y el riesgo de discriminación, asi como promover una mayor viabilidad de los centros especiales de empleo y los servicios ocupacionales donde estas personas trabajan o desarrollan su actividad.

\section{Palabras clave:}

envejecimiento, deterioro, empleo, discapacidad intelectual, trabajo ocupacional.

\footnotetext{
${ }^{1}$ Este artículo sintetiza el estudio de Edurne Elorriaga et al. (dirs.), Investigación sobre el envejecimiento y deterioro de las personas con discapacidad intelectual en el ámbito ocupacional y del empleo en Bizkaia, Loiu, Lantegi Batuak, 2011.
} 


\section{Introducción}

En el marco del proyecto "Envejecimiento y deterioro de las personas con discapacidad intelectual de Lantegi Batuak en el ámbito ocupacional y del empleo en Bizkaia", se han llevado a cabo varias actuaciones de investigación, así como reuniones internas de un grupo de reflexión experto -en el que ha tomado parte la dirección de Lantegi Batuak-y un seminario de participación con personas expertas del movimiento asociativo, para el análisis y diagnóstico de la situación, y el planteamiento de líneas de actuación. Todo ello se ha llevado a cabo desde el convencimiento de que el abordaje de las situaciones de deterioro/envejecimiento debe realizarse desde la perspectiva de las necesidades suplementarias de apoyo.

Los objetivos del proyecto en el ámbito específico de las modalidades de la ocupación y el empleo han sido los siguientes:

- Evitar la pérdida de puestos de trabajo entre el colectivo de personas con discapacidad intelectual que envejecen o sufren algún deterioro.

- Promover nuevas soluciones y dispositivos de apoyo que permitan mejorar la calidad de vida de las personas con discapacidad intelectual que envejecen, así como prevenir situaciones de deterioro.

- Mejorar las condiciones de ajuste sociolaboral, la formación, la adaptación de los puestos de trabajo y las medidas complementarias que permitan una mayor y mejor calidad de vida para el colectivo de personas con discapacidad intelectual que envejecen o sufren algún deterioro.

- Prevenir la discriminación laboral de las personas con discapacidad intelectual que envejecen y promover una plena igualdad de oportunidades en el ámbito del empleo.

- Prevenir las dificultades de viabilidad de los centros especiales de empleo y servicios ocupacionales a los que acuden las personas con discapacidad intelectual que envejecen o sufren algún deterioro.

En la Figura 1, se recoge el esquema de actuaciones realizadas. A partir de los resultados obtenidos en todas ellas, se ha elaborado el documento definitivo de conclusiones, retos, necesidades y propuesta de soluciones y dispositivos, que culmina la investigación realizada, para su posterior presentación y transferencia de resultados.

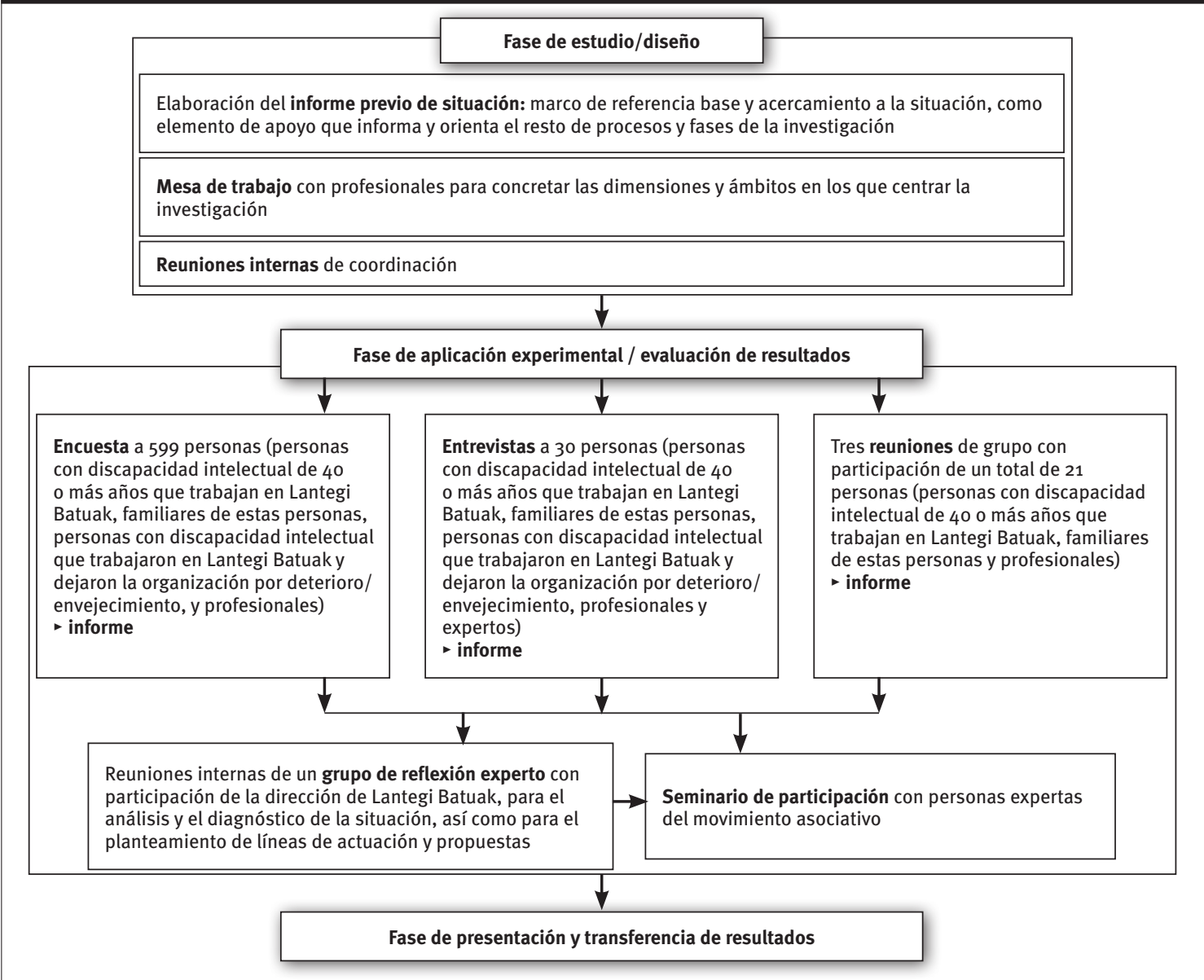

Fuente: Elaboración propia. 
En el citado marco, este artículo recoge los resultados de la investigación realizada, las conclusiones y las propuestas, elementos todos ellos fruto de dos procesos:

- Sesiones de trabajo del grupo de reflexión experto con participación de la dirección de Lantegi Batuak, obtenidos a partir de la valoración de los resultados de las actuaciones de investigación realizadas. Recogen el análisis, el diagnóstico de la situación, las líneas de actuación y las propuestas en relación con las situaciones de necesidades suplementarias de apoyo de las personas con discapacidad de Lantegi Batuak (entre ellas, por motivo de deterioro/envejecimiento).

- Seminario de participación con personas expertas del movimiento asociativo, para el contraste de las valoraciones, conclusiones y propuestas del grupo de reflexión.

El artículo tiene en cuenta, además, estas fuentes:

- Resultados obtenidos en los procesos de encuesta, entrevistas y reuniones de grupo, desarrollados entre los meses de junio y octubre de 2010.

- Diversos datos y referencias recogidas en el informe previo: bases conceptuales y referencias diversas con respecto a otros estudios de envejecimiento, marco jurídico, situación, y marco interno de Lantegi Batuak -datos generales, modelo de calidad de vida, Estudio de la incidencia de problemáticas asociadas en personas con discapacidad intelectual en Lantegi Batuak (Montero et al., 2006), Método de perfiles de adecuación de la tarea a la persona (Badiola et al., 2011)-, así como las conclusiones del seminario inicial de trabajo, en el que se concretaron dimensiones y ámbitos del estudio.

- Reflexiones del grupo interno de trabajo (dirigido por Lantegi Batuak) y otras personas expertas en este ámbito (seminario de participación).

\section{Antecedentes}

Diversas investigaciones ponen de relieve que el envejecimiento o deterioro se produce de manera prematura entre el colectivo de las personas con discapacidad intelectual, siendo, además, un motivo de necesidad suplementaria de apoyo. Así, el Estudio de la incidencia de problemáticas asociadas en personas con discapacidad intelectual en Lantegi Batuak (Montero et al., 2006), destaca que el 40,17\% de ellas tienen trastornos mentales, de conducta, pluridiscapacidades, o trastornos generalizados del desarrollo. Si se tiene en cuenta el porcentaje de personas con discapacidad intelectual con 50 o más años de la organización, casi la mitad (49,09\%) tienen problemáticas asociadas, y presentan, en consecuencia, necesidades suplementarias de apoyo. Destaca asimismo entre sus conclusiones la existencia de diferencias significativas en la intensidad de apoyos de las personas con discapacidad intelectual con 56 años o más, en relación a las de 55 años o menos, en especial, en cuanto se refiere a sus habilidades motoras. Además, alerta sobre el hecho de que, en los próximos cinco años, el número de personas dentro de este grupo en la organización casi va a duplicarse.

Es decir, Lantegi Batuak ha detectado el envejecimiento como uno de los motivos de doble diagnóstico y, en consecuencia, de necesidad suplementaria de apoyo, para las personas con discapacidad intelectual de la organización.

En relación con el deterioro o envejecimiento, también se han de considerar otros estudios y referencias. La Cartera de servicios sociales del movimiento FEAPS (2005) propone que el envejecimiento en estas personas se considere a partir de los 50 años, y lo planea como uno de los motivos que suponen necesidades específicas de apoyo y comportan intensidades de apoyo profesional más elevadas. El estudio Envejecimiento y deterioro de las personas con discapacidad intelectual en el ámbito del empleo en la Comunidad Foral de Navarra (FEAPS Navarra, 2005) también pone de relieve el envejecimiento prematuro del colectivo. Además, este deterioro/ envejecimiento, entre otros factores, incide en la pérdida o el deterioro de capacidades y competencias en el ámbito laboral. En concreto, a partir de los 50 años las personas con discapacidad intelectual presentan síntomas importantes de deterioro en los centros especiales de empleo, en aspectos que miden su capacidad de trabajo: la actitud, la perseverancia, la polivalencia, la disciplina, la perseverancia y la calidad de trabajo. La capacidad más afectada con la edad es la polivalencia.

Por su parte, el Informe Séneca. Envejecimiento y discapacidad intelectual en Cataluña 2000-2008 (Novell et al., 2008) concluye que las personas con discapacidad intelectual envejecen prematuramente: a excepción de las personas con síndrome de Down u otros síndromes, el envejecimiento prematuro de las personas con discapacidad intelectual leve y moderada es el resultado de la falta de programas de promoción de la salud, del reducido acceso a los servicios sanitarios, y de la baja calidad de la atención sanitaria y social recibida. Asimismo, entre sus resultados es destacable que tres de cada diez personas con discapacidad intelectual ligera y moderada mayores de 40 años o con grave deterioro de salud que están ocupadas en los diferentes servicios (tanto centros especiales de empleo como modalidades de servicio ocupacional) tienen un probable trastorno mental. En los diferentes ámbitos laborales/ ocupacionales, se constata una falta de detección de los problemas de salud mental y de las condiciones asociadas al envejecimiento que permitan ajustes personales y apoyos para evitar el desarraigo del entorno en que la persona se encuentra.

El estudio sobre las Necesidades de las personas con discapacidad intelectual en proceso de envejecimiento en Bizkaia (Aguado et al., 2007) pone de relieve que 
existen elementos diferenciales en el proceso de envejecimiento de este grupo frente al proceso de envejecimiento de la población general. Entre las conclusiones que plantea en el entorno laboral, destaca las consecuencias que el envejecimiento puede tener en un porcentaje importante de personas que realizan su actividad diaria en un contexto laboral (centro especial de empleo), por lo que parece necesario mencionar las posibles líneas de actuación que contribuyen a minimizar dichos efectos.

En el marco de la atención personalizada y de itinerarios individualizados que responden a cada una de las personas, se debe establecer la opción que más se adecue al/a la trabajador/a: cambio de actividad laboral, modificaciones en la actividad laboral actual, jubilación anticipada o paso a una actividad ocupacional. Para ello es necesario implementar, por un lado, mecanismos de tránsito como la flexibilidad en las jornadas laborales, facilitar jornadas reducidas o dedicaciones parciales; $y$, por otro, facilitar el acceso a servicios especializados de apoyo que contemplen reforzar aquellas áreas especialmente afectadas en la persona (prevención del deterioro, promoción de las habilidades comunicativas, etc.). Si la opción es la movilidad de los/as trabajadores/as a otras áreas o departamentos de la empresa, ello puede requerir dispositivos de reciclaje y/o capacitación, instrucción en el nuevo puesto y una monitorización más cercana hasta la adaptación al nuevo puesto. En caso de no ser posible el mantenimiento en una actividad laboral remunerada, procedería establecer itinerarios flexibles hacia la actividad en un Centro Ocupacional. En el fondo estamos hablando de desarrollar o actualizar las tareas y funciones de los SAP-Servicios de Ajuste Personal, ya contemplados desde los inicios del marco legislativo que regula el empleo protegido, de tal forma que contemplen las necesidades de estos/as trabajadores/as en su proceso de hacerse mayor. Por otro lado, la puesta en marcha de estas medidas puede implicar costes adicionales para la empresa y [que] requieran financiación por parte de las instituciones competentes en dicha materia (ibídem: 70).

Por último, el Plan para la Participación y Calidad de Vida de las Personas con Discapacidad en Bizkaia 2010-2013 (Diputación Foral de Bizkaia, 2010), entre las necesidades de las personas con discapacidad subraya que se aprecia un incremento de las necesidades complejas derivadas de las situaciones de pluridiscapacidad o multideficiencia, asociadas entre otros factores, al envejecimiento de la población.

\section{La realidad del deterioro/envejecimiento entre las personas con discapacidad intelectual que trabajan en Lantegi Batuak}

En el País Vasco, se registran unas 251.600 personas con discapacidad de 450 más años, de las cuales 133.900 viven en Bizkaia (Encuesta de Discapacidad,
Autonomía Personal y Situaciones de Dependencia 2008, Instituto Nacional de Estadística) ${ }^{2}$ : Dentro de las personas con discapacidad en Euskadi, 18.900 presentan dificultades de aprendizaje, aplicación de conocimientos y de desarrollo de tareas.

Los resultados de las actuaciones de investigación realizadas durante 2010 en el marco de este estudio ponen de relieve que el deterioro/envejecimiento es uno de los motivos por los que se producen necesidades suplementarias de apoyo entre las personas con discapacidad intelectual de Lantegi Batuak. También aparecen tales necesidades de apoyo por otras causas, como los trastornos de salud mental asociados, o los trastornos de conducta o de comportamiento.

En el momento en el que se inició el estudio, en Lantegi Batuak había 727 personas con discapacidad intelectual con edad igual o superior a 40 años: 366 en centro especial de empleo, de las cuales 249 eran hombres y 117 mujeres; y 361 en servicio ocupacional, de las cuales 227 eran hombres y 134 mujeres. La encuesta realizada revela que las personas con discapacidad intelectual de Lantegi Batuak comienzan a percibir síntomas de envejecimiento a partir de los 50 años. Sin embargo, también hay que tener en cuenta que muchas otras personas más jóvenes presentan síntomas de deterioro que requieren actuaciones transversales previas. Este fenómeno está dando lugar en Lantegi Batuak a problemáticas puntuales, que son objeto de una respuesta e intervención sistemática por parte de la organización. Se advierte una lógica tendencia incremental de estas situaciones a medio y largo plazo, de acuerdo con el propio avance de la edad de las personas.

El envejecimiento o deterioro incide en Lantegi Batuak con intensidad diversa, en función de distintos aspectos:

- Los efectos que esa situación tiene en función de que se trate de personas en centro especial de empleo o en servicio ocupacional.

- La propia realidad de la población actual de los centros: en los centros más antiguos hay personas más mayores que en otros más recientes.

- La diversidad existente dentro de la discapacidad intelectual, como elemento que influye directamente en la evolución y el envejecimiento de las personas y que genera grandes diferencias.

Seguidamente se recoge la caracterización de los efectos del deterioro/envejecimiento con respecto a cada una de las dimensiones de la calidad de vida, en coherencia con el Modelo de apoyos individuales... de Lantegi Batuak (Elorriaga et al., 2010) y a partir de los resultados obtenidos en el trabajo de campo desarrollado en este estudio (más detalles en Elorriaga et al.,2011: anexo 1).

${ }^{2}$ Se trata de una encuesta dirigida a hogares. Los datos sobre población con discapacidad según grupo de discapacidad no están desagregados por provincias. 


\subsection{Bienestar físico y material}

En la dimensión de bienestar físico y material, se percibe un progresivo deterioro de la salud y mayores dificultades físicas. Los síntomas más frecuentes que se manifiestan con el paso de la edad y que dificultan el desarrollo de la actividad laboral son: cansancio, dolores de espalda y piernas, pérdida de la vista y oído, dificultades para coger pesos, dificultades de movimiento y desplazamiento, problemas motores, menor motricidad, desorientación y déficits de atención. Otros síntomas del deterioro se manifiestan en la existencia de déficits en el autocuidado, el aseo, el vestido, la alimentación, los hábitos de vida saludable o el seguimiento de la salud.

Pero sobretodo son importantes las dificultades cognitivas - pérdida de memoria, mayores dificultades para el aprendizaje- y los trastornos asociados - problemas de salud mental, trastornos de conducta y de comportamiento-. De hecho, es en este ámbito donde más se observa el deterioro de estas personas con respecto a quienes no tienen discapacidad intelectual ${ }^{3}$.

Como consecuencia de este deterioro, se producen mayores niveles de dependencia, así como la necesidad de ajustes y adaptaciones en los puestos de trabajo, ayudas técnicas y productos de apoyo. También se manifiestan mayores dificultades para la autonomía en el traslado a los centros de trabajo.

La situación de deterioro/envejecimiento de las personas está unida al envejecimiento/deterioro de sus familias. En muchos casos, los síntomas de deterioro en la persona, o sus mayores demandas de apoyo, están directamente relacionadas con el deterioro de sus familias (familias que ya no pueden atenderles como hasta ahora, que requieren apoyos y cuidados por parte de la propia persona con discapacidad). Esto puede dar origen a situaciones de déficits en la higiene o el vestido, ausencias en el trabajo para atender situaciones de hospitalización o cuidado de familiares, situaciones de tristeza o duelo por enfermedad o fallecimiento, o falta de concentración, entre otras.

\subsection{Bienestar emocional}

En la dimensión de bienestar emocional también se observan síntomas de deterioro, por ejemplo, irritabilidad o cambios de humor. En algunos casos, se manifiesta aburrimiento y desmotivación con respecto a la actividad laboral. Son destacables también los sentimientos de incertidumbre ante el futuro, o de tristeza y duelo ante las situaciones de envejecimiento/deterioro de las familias.

Fomentar sentimientos de autoestima, autova-

${ }^{3}$ Es interesante citar que el Informe Séneca... (Novell et al., 2008), entre sus conclusiones, destaca que tres de cada diez personas con discapacidad intelectual ligera y moderada mayores de 40 años que están ocupadas en los diferentes servicios de empleo u ocupacionales tienen un probable trastorno mental. loración, aceptación e inclusión en el centro de trabajo resulta clave en esta etapa. Merece la pena destacar la satisfacción de las personas con discapacidad intelectual con la actividad que desarrollan, su sentimiento de superación y sus ganas de realizar bien su trabajo, porque esa actividad y sus resultados les hace sentirse realizados, porque perciben su contribución en el resultado obtenido con su trabajo.

\subsection{Desarrollo laboral}

Es fundamental la valoración y el efecto positivo que el trabajo tiene para estas personas: constituye una fuente de apoyo inestimable para su autoestima, autonomía y participación, y el desarrollo de una vida social y relacional. A este respecto, se percibe una incidencia directa del deterioro y los déficits en el nivel y ritmo de productividad, el rendimiento laboral, la capacidad de trabajo y aprendizaje y, en consecuencia, en menores posibilidades de reciclaje o reubicación. Se producen tiempos de inactividad cada vez más largos, con actividades menos significativas y valiosas, no adecuadas a las necesidades de desarrollo de estas personas. El deterioro provoca una mayor inadecuación de las personas a los contenidos actuales de los centros y la pérdida de capacidad asociada al tipo de actividad laboral que actualmente se desarrolla en ellos.

Se advierte la necesidad de mantener a estas personas con el mayor nivel de actividad posible, como la mejor forma de evitar y prevenir la aparición o el agravamiento de los efectos de deterioro. Además, se ha de mantener su actividad con un mínimo de trabajo real, incluso aunque la mayor parte del tiempo se desarrollen actividades no laborales y el taller, como centro de trabajo, pase a ser un recurso o una fuente más de apoyo.

\subsection{Relaciones interpersonales}

En muchos casos, las relaciones sociales que desarrollan estas personas se circunscriben a sus compañeras/os de trabajo y su familia. En principio, los resultados del estudio no reflejan una influencia del deterioro en el ámbito de las relaciones interpersonales, pero es apreciable un riesgo de soledad y aislamiento que se puede intensificar cuando la persona ya no está en Lantegi Batuak.

\subsection{Integración en la comunidad}

Existe un riesgo de aislamiento de estas personas si no se articulan apoyos suficientes y adecuados en el entorno comunitario, tanto en paralelo a su actividad laboral u ocupacional, como al finalizar ésta. Se han de permitir ajustes personales y apoyos para evitar el desarraigo del entorno en el que la persona vive. 


\subsection{Autodeterminación}

Existe un claro riesgo de pérdida de autodeterminación como consecuencia de la pérdida de capacidades asociada al deterioro/envejecimiento. Lo mismo cabe decir sobre las habilidades de autoprotección ante situaciones de vulneración de sus derechos y activación de mecanismos de defensa. También se observa una incidencia en la capacidad de participación en los diversos ámbitos del entorno comunitario.

\subsection{Derechos}

No existe un nivel suficiente de garantía de derechos en lo que respecta a su situación económica, tanto en caso de jubilación como de movilidad entre recursos distintos (centro especial de empleo, servicio ocupacional, centro de actividades diurnas/centro de día). No existe flexibilidad en el acceso, ni facilidad para pasar de un recurso a otro, o para compatibilizar servicios y prestaciones. Por último, tampoco se garantiza un sistema de valoración de la discapacidad al servicio de las personas.

\section{Deterioro/envejecimiento: efectos, necesidades y retos}

El Cuadro 1 sintetiza los efectos que la situación de deterioro/envejecimiento está suponiendo en Lantegi Batuak, así como sobre las necesidades y los retos que plantea.

De las conclusiones del estudio explicitadas en estos retos y necesidades con respecto a los diversos agentes, el diagnóstico de la situación que se obtiene es el siguiente: si bien las situaciones de deterioro 0 envejecimiento entre las personas de Lantegi Batuak $-\mathrm{y}$, con carácter general, del conjunto de personas con discapacidad en Bizkaia- es un fenómeno que, de manera generalizada, y a corto plazo, no se percibe como una situación de inminente necesidad, a medio/largo plazo la evolución apunta a una situación de deterioro más generalizada. Esta realidad comporta un importante reto, tanto para Lantegi Batuak como para el conjunto de la sociedad, las administraciones públicas y el movimiento asociativo, que exige anticipar respuestas y soluciones desde ahora.

Cuadro 1. Efectos del envejecimiento/deterioro en Lantegi Batuak, por agentes o grupos de interés

\begin{tabular}{|c|c|c|}
\hline $\begin{array}{l}\text { Agentes o } \\
\text { grupos de } \\
\text { interés }\end{array}$ & Efectos & Necesidades y retos, resultados que se han de conseguir \\
\hline $\begin{array}{l}\text { Personas con } \\
\text { discapacidad } \\
\text { de } 40 \text { o más } \\
\text { años }\end{array}$ & $\begin{array}{l}\text { - Progresiva inadecuación de sus capacidades, habilidades } \\
\text { y competencias a la oferta laboral actual. } \\
\text { - Insuficiente diversificación o adecuación de los conteni- } \\
\text { dos de la actividad laboral a sus necesidades específicas } \\
\text { de apoyo. } \\
\text { - Mayores dificultades para adaptarse a la oferta laboral } \\
\text { en servicios o enclaves laborales: los perfiles con } \\
\text { mayores dificultades requieren y demandan un marco de } \\
\text { actividades estable, con ubicación en centros especiales } \\
\text { de empleo -no en servicios ocupacionales-, con conte- } \\
\text { nidos pautados de manipulación dentro de una cadena } \\
\text { productiva. } \\
\text { - Demanda de nuevas alternativas y combinación de activi- } \\
\text { dades, laborales y no laborales, orientadas a favorecer el } \\
\text { mantenimiento de capacidades y a evitar los efectos del } \\
\text { envejecimiento/deterioro. } \\
\text { - Necesidad de adaptaciones y mayor flexibilidad de las } \\
\text { condiciones laborales, por motivos de conciliación o } \\
\text { por sus propias dificultades asociadas al deterioro/ } \\
\text { envejecimiento. } \\
\text { - Incremento de la demanda de atención con respecto a los } \\
\text { profesionales de apoyo. } \\
\text { - Situaciones de desigualdad e insuficiencia de garantía de } \\
\text { derechos en caso de jubilación. Desincentivación o impo- } \\
\text { sibilidad de cumplimiento de requisitos para el acceso } \\
\text { efectivo a los recursos existentes, o para la movilidad } \\
\text { entre ellos. } \\
\text { - Situaciones de desigualdad en las declaraciones o los } \\
\text { reconocimientos de incapacidad permanente de la Segu- } \\
\text { ridad Social. No existe un sistema con carácter institu- } \\
\text { cional y garantías suficientes de igualdad que determine } \\
\text { cuándo una persona ha de acceder a los diversos recur- } \\
\text { sos (centros especiales de día, servicios ocupacionales, } \\
\text { centros de día), ni con respecto a los itinerarios óptimos } \\
\text { para atender las necesidades específicas de apoyo en el } \\
\text { ámbito laboral y ocupacional. }\end{array}$ & $\begin{array}{l}\text { Reto: que las personas con discapacidad intelectual, } \\
\text { en proceso de deterioro/envejecimiento tengan cabida } \\
\text { en Lantegi Batuak, desarrollen una actividad laboral u } \\
\text { ocupacional valiosa y significativa, en el marco de la misión } \\
\text { y valores de Lantegi Batuak, y tengan asegurados todos los } \\
\text { apoyos y recursos necesarios para su desarrollo y calidad } \\
\text { de vida. } \\
\text { Esto supone que las personas con discapacidad intelectual } \\
\text { en proceso de deterioro/envejecimiento puedan: } \\
\text { - En el ámbito interno (Lantegi Batuak): } \\
\text { - Disponer de una oferta diversa y suficiente de apoyos } \\
\text { y contenidos de actividad, laboral y no laboral, } \\
\text { adecuados a sus necesidades específicas. } \\
\text { - Contar con mecanismos adecuados para la } \\
\text { prevención y detección tempranas de situaciones de } \\
\text { envejecimiento/deterioro. } \\
\text { - Seguir disponiendo de una oferta laboral, en centros } \\
\text { especiales de empleo, adaptada a sus necesidades. } \\
\text { - En el ámbito externo (sociedad, entorno): } \\
\text { - Tener garantizado en cualquier situación laboral u } \\
\text { ocupacional el nivel de ingresos de, como mínimo, la } \\
\text { renta de garantía de ingresos. } \\
\text { - Disponer de una oferta adecuada y suficiente de } \\
\text { apoyos, servicios y recursos, tanto especializados } \\
\text { como generales de ámbito comunitario. } \\
\text { - Disponer de garantías efectivas de acceso y movilidad } \\
\text { entre recursos existentes, sin que ello comporte } \\
\text { penalización en sus ingresos. } \\
\text { - Tener garantizado su derecho a unos recursos } \\
\text { económicos adecuados y suficientes en el momento } \\
\text { de su jubilación. } \\
\text { - Tener garantizado un sistema homogéneo de } \\
\text { valoración de la incapacidad: homogeneización de las } \\
\text { características de las personas con discapacidad para } \\
\text { de sus necesidades específicas de apoyo, pueden } \\
\text { acceder a los diversos recursos de empleo o a } \\
\text { diferentes tipo de actividad ocupacional. }\end{array}$ \\
\hline
\end{tabular}




\begin{tabular}{|c|c|c|}
\hline $\begin{array}{l}\text { Agentes o } \\
\text { grupos de } \\
\text { interés }\end{array}$ & Efectos & Necesidades y retos, resultados que se han de conseguir \\
\hline Familiares & $\begin{array}{l}\text { - Inseguridad y desconocimiento con respecto a la forma } \\
\text { de actuar ante estas nuevas situaciones. } \\
\text { - Preocupación y miedo ante el futuro, por ejemplo, en } \\
\text { temas como el relevo en el cuidado de sus familiares con } \\
\text { discapacidad. } \\
\text { - Situaciones coincidentes de deterioro/envejecimiento } \\
\text { tanto de la persona con discapacidad como de las } \\
\text { propias familias. } \\
\text { - Necesidad de recursos de apoyo a las familias (servicios } \\
\text { de ocio, respiro, apoyo a domicilio). }\end{array}$ & $\begin{array}{l}\text { Reto: que las familias obtengan apoyo adecuado y } \\
\text { suficiente ante las situaciones de envejecimiento/deterioro } \\
\text { de sus familiares con discapacidad. } \\
\text { Esto supone que las que las familias puedan: } \\
\text { - En el ámbito interno (Lantegi Batuak): } \\
\text { - Disponer de una comunicación continua con la entidad } \\
\text { acerca de la evolución de las necesidades de su } \\
\text { familiar con discapacidad. } \\
\text { - Disponer de la orientación y el apoyo suficientes para } \\
\text { acceder a las prestaciones y recursos existentes. } \\
\text { - En el ámbito externo (sociedad, entorno): } \\
\text { - Disponer de una respuesta especializada de } \\
\text { orientación y asesoramiento, con la máxima } \\
\text { antelación posible. } \\
\text { - Disponer de una oferta suficiente y adecuada de } \\
\text { servicios y recursos de apoyo (apoyo a familias, } \\
\text { respiro, apoyo a domicilio). } \\
\text { - Disponer de apoyos suficientes para facilitar la } \\
\text { tramitación y el acceso a los diversos recursos. }\end{array}$ \\
\hline Profesionales & $\begin{array}{l}\text { - Exigencia de una mayor dedicación, desarrollo de funcio- } \\
\text { nes para las cuales no disponen de tiempo suficiente, no } \\
\text { están preparados o que requieren la respuesta de otros } \\
\text { perfiles profesionales más adecuados. } \\
\text { - Actitudes diversas ante la situación: } \\
\text { - Preocupación/desazón ante las situaciones de } \\
\text { deterioro/envejecimiento. } \\
\text { - Actitud de implicación activa en la activación de } \\
\text { soluciones. } \\
\text { - Rechazo a la permanencia en los centros de personas } \\
\text { que ya no son productivas, y a la priorización de la } \\
\text { actividad productiva frente a las necesidades de la } \\
\text { persona. } \\
\text { - Conformismo ante las dificultades que esta situación } \\
\text { puede plantear. Se tiende a mantener a la persona } \\
\text { en la tarea en la que está, aunque esté sin producir o } \\
\text { aburrida, antes que intentar realizar cualquier cambio } \\
\text { dirigido a activarla o estimularla, ya que esto requiere } \\
\text { más tiempo y dedicación. }\end{array}$ & $\begin{array}{l}\text { Reto: alinear y unificar la respuesta de las/los } \\
\text { profesionales hacia la consecución de la mayor calidad de } \\
\text { vida posible para las personas con discapacidad intelectual } \\
\text { en situación de deterioro/envejecimiento de Lantegi } \\
\text { Batuak. } \\
\text { Esto supone que las/los profesionales puedan: } \\
\text { - Conocer la estrategia y las actuaciones de la organización } \\
\text { respecto a las personas con discapacidad intelectual en } \\
\text { proceso de deterioro/envejecimiento, y participar en su } \\
\text { despliegue y desarrollo. } \\
\text { - Disponer de las competencias y condiciones necesarias } \\
\text { para el adecuado desarrollo de las funciones de apoyo a } \\
\text { estas personas. } \\
\text { - Disponer de formación y competencias para mejorar la } \\
\text { detección, prevención e intervención ante síntomas y } \\
\text { situaciones de deterioro/envejecimiento de las personas } \\
\text { con discapacidad. }\end{array}$ \\
\hline $\begin{array}{l}\text { Centros } \\
\text { especiales } \\
\text { de empleo, } \\
\text { servicios } \\
\text { ocupacionales } \\
\text { y otros } \\
\text { dispositivos }\end{array}$ & $\begin{array}{l}\text { - Periodos largos de inactividad por parte de algunas } \\
\text { personas en los centros. } \\
\text { - Inadecuación de los puestos de trabajo como conse- } \\
\text { cuencia de la pérdida de capacidad asociada al tipo de } \\
\text { actividad laboral que actualmente se desarrolla. } \\
\text { - Desigual distribución de cargas de trabajo. } \\
\text { - Número de profesionales de apoyo insuficiente o con } \\
\text { perfil de atención inadecuado. } \\
\text { - Necesidad de nuevos contenidos de actividad, más ade- } \\
\text { cuados a las capacidades de estas personas, orientados } \\
\text { a su mantenimiento y a la prevención de los efectos del } \\
\text { deterioro/envejecimiento. }\end{array}$ & $\begin{array}{l}\text { Reto: conseguir unas condiciones y una oferta de } \\
\text { actividades en los centros y servicios que permitan a } \\
\text { las personas con discapacidad intelectual en proceso } \\
\text { de deterioro/envejecimiento tener cabida en aquéllos y } \\
\text { desarrollar una actividad laboral u ocupacional valiosa y } \\
\text { significativa. } \\
\text { Esto supone: } \\
\text { - Desplegar una oferta de actividad diversificada, de } \\
\text { contenido laboral y no laboral, orientada a conseguir el } \\
\text { máximo estímulo y desarrollo de las capacidades y poten- } \\
\text { cialidades, evitando y retrasando al máximo la aparición } \\
\text { de síntomas de deterioro/envejecimiento. } \\
\text { - Implementar espacios diversificados para el desarrollo } \\
\text { de actividades de contenido no laboral. } \\
\text { - Organizar los equipos profesionales, en número y de } \\
\text { perfiles adecuados, teniendo en cuenta los apoyos } \\
\text { suplementarios requeridos por las trabajadoras/es con } \\
\text { discapacidad, por deterioro/envejecimiento o por otros } \\
\text { motivos. }\end{array}$ \\
\hline $\begin{array}{l}\text { Lantegi } \\
\text { Batuak (como } \\
\text { organización) }\end{array}$ & $\begin{array}{l}\text { - Insuficiencia/inadecuación de la oferta actual de los } \\
\text { centros especiales de empleo y servicios ocupacionales } \\
\text { laboral para atender las necesidades suplementarias de } \\
\text { apoyo de estas personas. } \\
\text { - Necesidad de equilibrar la respuesta a nuevas nece- } \\
\text { sidades y la viabilidad/sostenibilidad de las diversas } \\
\text { medidas, en un escenario a medio/largo plazo. }\end{array}$ & $\begin{array}{l}\text { Reto: continuar incluyendo a las personas con } \\
\text { discapacidad con necesidades específicas de apoyo, } \\
\text { entre ellas, las personas con discapacidad intelectual } \\
\text { en deterioro/envejecimiento, en el conjunto de la } \\
\text { organización. } \\
\text { Esto supone: } \\
\text { - Innovar en soluciones y respuestas. } \\
\text { - Visibilizar la actividad que las personas con discapacidad } \\
\text { desarrollan en Lantegi Batuak, sus resultados y valor } \\
\text { añadido. } \\
\text { - Contribuir a la reivindicación de actuaciones precisas, } \\
\text { por parte de las administraciones públicas, dirigidas } \\
\text { hacia una respuesta global que haga efectivos todos los } \\
\text { derechos de las personas con discapacidad intelectual y } \\
\text { sus familias. } \\
\text { - Incluir los resultados de este trabajo como un elemento } \\
\text { de análisis, diagnóstico y formulación de estrategias } \\
\text { y actuaciones, en relación con el reto del deterioro/ } \\
\text { envejecimiento, en el proceso de elaboración del plan } \\
\text { estratégico que lleve a cabo Lantegi Batuak. }\end{array}$ \\
\hline
\end{tabular}




\begin{tabular}{|c|c|c|}
\hline $\begin{array}{l}\text { Agentes o } \\
\text { grupos de } \\
\text { interés }\end{array}$ & Efectos & Necesidades y retos, resultados que se han de conseguir \\
\hline $\begin{array}{l}\text { Sociedad, } \\
\text { entorno }\end{array}$ & $\begin{array}{l}\text { - Insuficiencia/inadecuación de la oferta actual de } \\
\text { recursos y apoyos a las personas con discapacidad } \\
\text { intelectual en situación de deterioro/envejecimiento y a } \\
\text { sus familias. } \\
\text { - Insuficiencia/inadecuación de los recursos comunitarios } \\
\text { del entorno como oferta actual válida o suficiente ante } \\
\text { estas necesidades. } \\
\text { - Insuficiencia de condiciones que permitan de forma } \\
\text { efectiva a todas las personas que los requieran acceder } \\
\text { a los recursos existentes por parte de todas las personas } \\
\text { que los requieran. } \\
\text { - Insuficiencia de garantías con respecto al derecho a } \\
\text { estas personas a unos recursos económicos adecuados y } \\
\text { suficientes en el momento de su jubilación. }\end{array}$ & $\begin{array}{l}\text { Reto: avanzar hacia un nuevo sistema de organización de } \\
\text { los apoyos con respecto a las personas con discapacidad } \\
\text { intelectual que presentan necesidades especiales, por } \\
\text { motivo de deterioro/envejecimiento o por otras causas, } \\
\text { con un sistema donde la oferta de apoyos se gestione en } \\
\text { función de la demanda. } \\
\text { Esto supone: } \\
\text { - Contar con una oferta adecuada, diversa y suficiente de } \\
\text { servicios, recursos y apoyos, que garantice condiciones } \\
\text { de acceso a los recursos y movilidad entre ellos, de } \\
\text { acuerdo con las necesidades de las personas. } \\
\text { - Contar con una oferta adecuada y suficiente de apoyo } \\
\text { para las familias. } \\
\text { - Asegurar el derecho de estas personas a unos recursos } \\
\text { económicos adecuados y suficientes en el momento de } \\
\text { su jubilación. }\end{array}$ \\
\hline
\end{tabular}

Fuente: Elaboración propia.

La solución práctica a estas nuevas situaciones de necesidad que se vienen produciendo como consecuencia del deterioro o envejecimiento las personas con discapacidad se ha de articular desde la perspectiva de las necesidades suplementarias de apoyo, que han de incluir actuaciones con respecto a las personas con discapacidad intelectual en situación de deterioro/envejecimiento, trastornos de salud mental asociados, y trastornos de conducta o de comportamiento, entre otras circunstancias.

En este marco, Lantegi Batuak, en coherencia con su visión, misión y valores, afronta la problemática del deterioro/envejecimiento desde la apuesta estratégica por que las personas que se deterioran o envejecen, o que, por cualquier otro motivo, presentan necesidades suplementarias de apoyo, puedan seguir trabajando en Lantegi Batuak, si así lo escogen, con las condiciones y la diversidad de apoyos necesarios para hacerlo posible.

Desde esta perspectiva global, el diagnóstico permite observar la necesidad de disponer de un nuevo sistema de empleo, ocupación y apoyos capaz de dar una respuesta efectiva y no discriminatoria a las necesidades evolutivas de las personas con discapacidad intelectual que envejecen o sufren deterioros significativos de salud, o tienen necesidad de apoyo suplementario por otras causas. Asimismo, en el plano interno se pone de manifiesto la necesidad de Lantegi Batuak de adecuar la oferta y la diversidad de apoyos de carácter suplementario que puedan necesitar estas personas, atendiendo a la diversidad de estas necesidades.

En concreto, Lantegi Batuak, como organización que genera en Bizkaia el mayor número de oportunidades de empleo para las personas con discapacidad, con una importante solvencia técnica, una metodología de trabajo innovadora, con herramientas para la adaptación de los apoyos y trayectoria comprometida con la calidad de vida de sus trabajadoras/es, en línea con las actuaciones que ya viene desarrollando e impulsando, debe seguir asumiendo un papel proactivo, participando activamente en impulsar condiciones, tanto en el entorno como en el ámbito interno de su organización, para ofrecer una adecuada respuesta a la evolución de las necesidades de estas personas, en la construcción de este nuevo sistema.

El escenario ofrece importantes oportunidades que Lantegi Batuak debe aprovechar para impulsar adaptaciones normativas y del entorno, así como para adecuar sus condiciones y dispositivos internos al modelo de empleo protegido, la asunción de políticas activas de empleo por parte de Gobierno Vasco, o a la sensibilidad de la Diputación Foral de Bizkaia y sus políticas alineadas con la apuesta estratégica de Lantegi Batuak por las personas.

En concreto, el Plan para la Participación y Calidad de Vida de las Personas con Discapacidad en Bizkaia 2010-2013 (Diputación Foral de Bizkaia, 2010), entre sus conclusiones de diagnóstico, observa una necesidad creciente y diversificada de adaptar las prestaciones y servicios a las necesidades específicas de apoyo propias de cada etapa del itinerario vital de las personas con discapacidad (infancia y adolescencia, edad adulta y deterioro/envejecimiento), y ve preciso adaptar o buscar nuevas respuestas a estas necesidades emergentes. Además, entre sus objetivos prevé adecuar los servicios a la evolución de las necesidades de las personas con discapacidad, orientando su desarrollo hacia la progresiva incorporación del modelo de participación y calidad de vida en la comunidad, lo que supone, entre otras, actuaciones en clave de flexibilización y combinación de recursos.

\section{Visión: propuesta-marco de un nuevo sistema de organización de los apoyos para personas con discapacidad que presentan necesidades suplementarias de apoyo}

A la vista de los efectos que la situación de deterioro o envejecimiento está suponiendo en Lantegi Batuak, y teniendo en cuenta la diversidad de planteamientos 
y propuestas expresadas por las personas que han participado en este estudio, este apartado recoge la visión de la entidad para orientar las propuestas, las líneas de actuación, las soluciones y los dispositivos dirigidos a ofrecer una respuesta global a este fenómeno, con requerimientos de condiciones y actualizaciones, tanto en el ámbito interno de Lantegi Batuak como en el externo (administraciones públicas en su diversos niveles, movimiento asociativo y sociedad en su conjunto).

Con carácter previo a la formulación de esta visión, se recogen varias consideraciones y premisas con respecto al sistema de apoyos en el ámbito laboral y ocupacional de las personas con discapacidad. Tales consideraciones y premisas se tienen en cuenta en la construcción de la visión, la estrategia y las actuaciones de Lantegi Batuak frente a las situaciones de deterioro/envejecimiento de sus trabajadores/as con discapacidad intelectual, así como a la de otras personas con necesidades suplementarias de apoyo.

\subsection{Consideraciones previas}

- Nos hallamos en un escenario de necesidad de actualización del vigente modelo de empleo protegido y, por extensión, del sistema de organización de los apoyos para las personas con discapacidad en el ámbito de empleo y de la actividad ocupacional.

- El marco para afrontar la problemática del envejecimiento es la propia apuesta estratégica de la organización por las personas.

- El hecho de analizar y plantear mejoras en relación con el envejecimiento/deterioro no supone que se esté juzgando o poniendo en entredicho la sostenibilidad del modelo de Lantegi Batuak.

- Se trata de una problemática que no está demandando soluciones o respuestas urgentes, pero que sí requiere una progresiva incorporación de medidas y soluciones (internas y externas) a medio/largo plazo, en orden a una estrategia decidida, asumida y comunicada.

- El abordaje de las situaciones de deterioro/envejecimiento debe realizarse desde la perspectiva de las necesidades suplementarias de apoyo, incluyendo la intervención y las actuaciones con respecto a las personas con discapacidad intelectual en situación de deterioro/envejecimiento, trastornos de salud mental asociados, trastorno de conducta o de comportamiento, entre otras.

- Hay que tener en cuenta que la presencia de otro tipo de trastornos: de conducta o de comportamiento, o la enfermedad mental asociada, están generando situaciones de mayor dificultad en la intervención de los profesionales.

\subsection{Premisas de la visión de Lantegi Batuak}

\subsubsection{Derecho al trabajo, la autonomía personal, la libertad de elección y a una contraprestación justa}

Cualquier planteamiento en relación con el empleo de las personas con discapacidad y, en particular, de aquellas que presentan necesidades suplementarias de apoyo, se debe realizar:

- Con plena garantía de su derecho al trabajo, la autonomía personal y la libertad de elección.

- Con plena garantía de su derecho a una contraprestación justa que compense, en su caso, su déficit de productividad o rendimiento.

Ambas premisas se basan en la Convención de las Naciones Unidas sobre los Derechos de las Personas con Discapacidad (arts. 1.1, 3, 19, 26 y 27) y en la Ley $51 / 2003$, de 2 de diciembre, de Igualdad de Oportunidades, no Discriminación y Accesibilidad Universal de las Personas con Discapacidad (LIONDAU, arts. 8.1. y 8.2).

\subsubsection{Condiciones que se deben asegurar en todo caso}

Cualquier persona con discapacidad intelectual que sufra un proceso de deterioro o envejecimiento prematuro, según la valoración de Lantegi Batuak, tiene que poder:

- Continuar trabajando, todo el tiempo que sea posible, si así lo decide, disponiendo, en su caso, de los dispositivos adecuados para ofrecerle la oportunidad de seguir realizando actividades productivas significativas.

- Escoger entre una diversidad de alternativas adecuadas a sus necesidades de apoyo suplementarias.

- Optar, si así lo decide, por combinar distintas opciones de protección social (incapacidad laboral, jubilación anticipada, apoyos sociales).

- Tener siempre garantizado, como mínimo, un nivel de ingresos equivalente al $100 \%$ de la renta de garantía de ingresos, cualquiera que sea su situación laboral o actividad.

A este último respecto, es preciso decir que la Ley de Servicios Sociales de Euskadi propone nuevos derechos subjetivos para las personas, de manera que los servicios sociales se configuran como un elemento adicional de garantía para el bienestar de la ciudadanía. La ley viene a completar un sistema de servicios sociales que ha ido configurando, en Euskadi, un nuevo pilar para la protección social de los más desfavorecidos. En este mismo sentido, se aprobaron la Ley 12/1998 contra la Exclusión Social y la Ley 10/2000 de Carta de Derechos Sociales. Esta última consagró el derecho a una renta básica, garantizando, por un lado, la existencia misma de dicha 
prestación y, por otro, el derecho de todas las personas a percibir unos ingresos en cuantía suficiente para ejercer sus derechos de ciudadanía, o derechos sociales básicos, y evitar así la exclusión social por motivos económicos, eliminando situaciones de pobreza. Luego tuvo una modificación, que dio lugar a la actual renta de garantía de ingresos.

Creemos que el desarrollo normativo posterior a la Ley de Servicios Sociales deberá tener en cuenta situaciones de injusticia social que pueden producirse, por lo que pensamos que se debería asegurar que la suma del valor de las prestaciones públicas percibidas por las personas usuarias del servicio ocupacional, junto con las gratificaciones percibidas como prestación propia, superen en todo caso el valor de la renta de garantía de ingresos, de manera que se garantice a la persona con discapacidad, individualmente considerada, los mismos derechos ciudadanos establecidos para el resto de las personas.

\subsubsection{Condiciones que permitan el desarrollo de una actividad laboral u ocupacional, productiva, significativa, reconocida y valorada}

Hemos de avanzar para conseguir oportunidades laborales y condiciones, internas y externas, que permitan que todas las personas con discapacidad intelectual puedan desarrollar una actividad laboral u ocupacional, productiva, significativa, reconocida y valorada. Esto supone, entre otros cambios, construir un nuevo sistema de organización de los apoyos dirigido a las personas con discapacidad intelectual que presentan necesidades especiales, por motivo de deterioro/envejecimiento o por otras causas; un sistema donde la oferta de apoyos se gestione en función de las necesidades y la demanda de dichos apoyos.

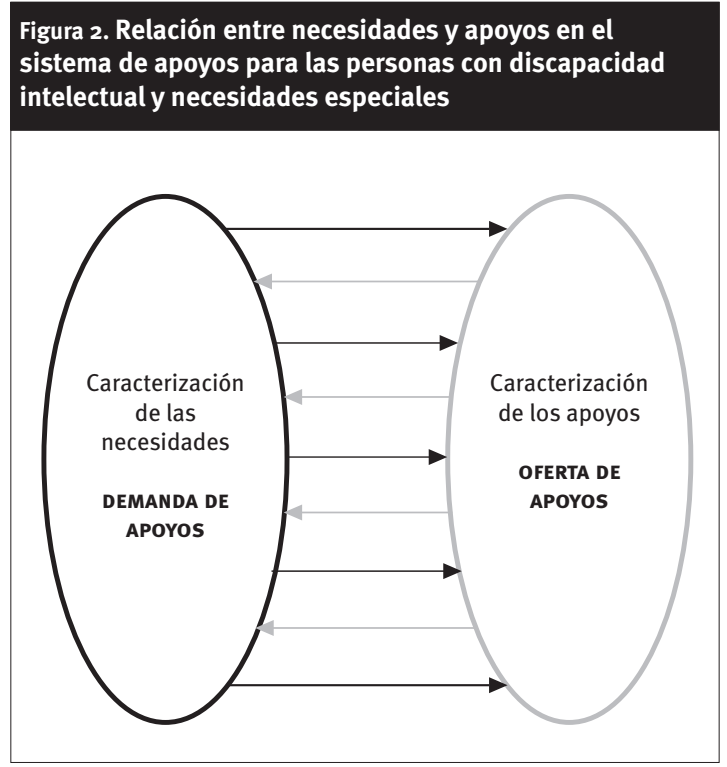

Fuente: Elaboración propia.
Se trata de ofertar un mayor abanico de posibilidades de empleo, ocupación, actividades diurnas y respuestas intermedias, con elementos de apoyo diverso y complementario. Estas vías han de permitir la promoción y el acceso a fórmulas con mayores posibilidades de desarrollo laboral, y, en el caso de personas en situación de deterioro o envejecimiento, fórmulas de adecuación a esas necesidades específicas de apoyo. En este sentido, Lantegi Batuak apuesta por lograr modelos y metodologías innovadoras a partir de la experiencia práctica y la investigación aplicada.

\subsection{Propuesta de un nuevo sistema de organización de los apoyos para las personas con discapacidad que presentan necesidades suplementarias de apoyo}

De acuerdo con las consideraciones y premisas expresadas, la visión de Lantegi Batuak es la de disponer de un nuevo sistema de organización de los apoyos para las personas con discapacidad de Lantegi Batuak que presentan necesidades suplementarias de apoyo, con un diseño de itinerarios circulares y compatibilidad de medidas de apoyo. Esta visión informa el planteamiento de estrategias y líneas de actuación, tanto en el plano interno como en relación con agentes externos: es el caso de las reivindicaciones de cambios normativos o iniciativas que han de adoptar las administraciones públicas de ámbito competencial diverso.

Se trata de diseñar y desarrollar un sistema de organización de apoyos a la actividad laboral y ocupacional que permita combinarlos y compatibilizarlos, y concretar itinerarios y dispositivos de la oferta, en función de los perfiles de necesidad, bien sea por deterioro/envejecimiento o por otros motivos, comprendiendo, a partir de los recursos actuales, la posibilidad de combinaciones diversas entre:

- Empleo ordinario.

- Empleo con apoyo.

- Empleo especial (centros especiales de empleo).

- Servicio ocupacional (programas con diferentes intensidades de apoyo).

- Centros de día y centros de actividades de día.

- Recursos económicos complementarios.

- Otras prestaciones y recursos, tanto de carácter sociolaboral como de otro tipo.

La consecución de un sistema de estas características requiere adaptaciones internas, como organización, y, sobretodo, cambios externos: adaptaciones y conciliación de normativa, y cambios estructurales, con implicación de distintos niveles competenciales (Ministerio de Empleo y Seguridad Social, Departamento de Empleo y Asuntos Sociales del Gobierno Vasco, Departamento de Acción Social de la Diputación Foral de Bizkaia).

El sistema habría de respetar, en cualquier caso, la voluntad y la libertad de elección de las personas. 
Cuadro 2. Posibles combinaciones de recursos de apoyo, según la situación de la personas con discapacidad intelectual con necesidades especiales

\begin{tabular}{|c|c|c|c|}
\hline \multirow{3}{*}{$\begin{array}{l}\text { Sistemas de } \\
\text { respuesta }\end{array}$} & \multicolumn{3}{|c|}{ Posibles situaciones de la persona con discapacidad intelectual que presenta necesidades suplementarias de apoyo } \\
\hline & \multicolumn{2}{|l|}{ En centros especiales de empleo } & \multirow{2}{*}{ En servicio ocupacional } \\
\hline & Jornada completa & Jornada parcial (25\%-75\%) & \\
\hline Seguridad Social & & $\begin{array}{l}\text { Acceso, en su caso, a los regímenes } \\
\text { de incapacidad permanente total o } \\
\text { incapacidad permanente parcial en la } \\
\text { parte de jornada laboral no cubierta. }\end{array}$ & $\begin{array}{l}\text { Percepción, en su caso, de } \\
\text { la pensión por incapacidad } \\
\text { permanente que corresponda (de } \\
\text { acuerdo con lo que hubiera podido } \\
\text { cotizar previamente en centro } \\
\text { especial de empleo o en empleo } \\
\text { ordinario). }\end{array}$ \\
\hline $\begin{array}{l}\text { Políticas activas de } \\
\text { empleo }\end{array}$ & $\begin{array}{l}\text { Garantía de, como mínimo, la renta } \\
\text { de garantía de ingresos. }\end{array}$ & $\begin{array}{l}\text { Salario correspondiente según la } \\
\text { jornada laboral desarrollada (de } \\
\text { forma que se garantice, junto con la } \\
\text { Seguridad Social, como mínimo, la } \\
\text { renta de garantía de ingresos). }\end{array}$ & \\
\hline Servicios sociales & $\begin{array}{l}\text { Apoyos con intensidad gradual, } \\
\text { según necesidad. }\end{array}$ & $\begin{array}{l}\text { Apoyos con intensidad gradual, según } \\
\text { necesidad. }\end{array}$ & $\begin{array}{l}\text { Apoyos con intensidad gradual, } \\
\text { según necesidad, y renta de garantía } \\
\text { de ingresos garantizada. }\end{array}$ \\
\hline
\end{tabular}

Fuente: Elaboración propia.

Además, deberá permitir el acceso de las personas en centros especiales de empleo que se encuentren en una situación de deterioro o envejecimiento a las prestaciones de incapacidad permanente de la Seguridad Social. De esta forma, habría de ser posible que, cuando una persona así lo requiera como consecuencia de deterioro o envejecimiento, pudiera seguir trabajando en un centro especial de empleo con una jornada parcial (del $25 \%, 50 \% 075 \%$ ) y, al mismo tiempo, en la parte de jornada no cubierta, percibiera la correspondiente pensión por incapacidad permanente -total o parcial- (del 75\%, 50\% o $25 \%$ ). En el caso de personas en servicio ocupacional, tal combinación también debería ser posible siempre que la persona hubiera generado previamente su derecho a percibir pensión por incapacidad permanente de la Seguridad Social, por haber cotizado el tiempo requerido en centro especial de empleo o en empleo ordinario. Todo ello, además, debería poder combinarse con los apoyos precisos del sistema de servicios sociales, con intensidad gradual, según la necesidad que la persona presenta.

El Cuadro 3 resume este sistema de apoyo a las actividades laborales desde la perspectiva de los diversos sistemas de respuesta -Seguridad Social, políticas activas de empleo y servicios sociales-, y según la diversidad de situaciones de la persona -centro especial de empleo o servicio ocupacional-.

Según el perfil de necesidad de apoyo que presente (alto, medio o bajo), la persona con discapacidad habría de tener la oportunidad de recibir apoyos diversos de los distintos sistemas de respuesta, con posibilidad de combinarlos. En especial, y cuando así proceda, sería deseable compatibilizar las prestaciones de incapacidad permanente -total o parcialcon la continuidad en un centro especial de empleo en jornada parcial. Todo ello sin perjuicio de que pudiera proceder, si la persona cumple los requisitos establecidos, el reconocimiento de situación de gran invalidez, incapacidad permanente absoluta para todo el trabajo o jubilación anticipada.

La identificación de los diversos escenarios y combinaciones de apoyo a las actividades laborales u ocupacionales habrá de venir determinada por:

- El perfil de necesidad de apoyo de las personas, lo que requiere caracterizarlas en función del deterioro de sus capacidades, como consecuencia de envejecimiento o por cualquier otro motivo.

- La aplicación de una herramienta y un protocolo para detectar el deterioro/envejecimiento, la articulación de perfiles de necesidad de apoyo y el establecimiento de programas de apoyo.

\section{Perfil de necesidad de apoyo: caracterización de las personas en función del deterioro de sus capacidades como consecuencia de envejecimiento o por cualquier otro motivo}

Seguidamente se propone una caracterización de los perfiles de necesidad de las personas de Lantegi Batuak, basada en su Método de perfiles de adecuación de la persona a la tarea (Badiola et al., 2011), que diferencia tres niveles según la intensidad de apoyo requerida: alto, medio y bajo. Cada uno de estos perfiles se define, según las consecuencias del deterioro/envejecimiento $u$ otras situaciones que suponen la necesidad de apoyos suplementarios, en relación con:

- Las variables que recoge el citado método en los siguientes aspectos del perfil de la persona: autonomía personal, procesado de la información, aptitudes físicas y actitudes ante el trabajo. 
- Variables tomadas de los resultados de este estudio con la finalidad de completar la caracterización en los casos de deterioro/envejecimiento en los ámbitos físico, cognitivo, relacional y emocional. En concreto, se hace referencia a: cansancio, memoria, irritabilidad y cambios de humor, tristeza y apatía, y aislamiento.
- Los apoyos que se ofertan en Lantegi Batuak a las personas con discapacidad intelectual, que constituyen una parte central de su Modelo de apoyos individuales... (Elorriaga et al., 2010) y se articulan sobre las siete dimensiones de calidad de vida que se explican más detenidamente en dicha publicación. En el Cuadro 3 se detallan esos apoyos.

Cuadro 3. Apoyos ofrecidos, agrupados por dimensiones de la calidad de vida

\begin{tabular}{|c|c|}
\hline Dimensiones & Apoyos \\
\hline Bienestar físico y material & $\begin{array}{l}\text { - Control de comida y alimentación. } \\
\text { - Ayuda para el traslado y la movilidad. } \\
\text { - Ayuda en el aseo y vestido. } \\
\text { - Acciones de seguimiento de la salud. } \\
\text { - Acciones para el manejo del dinero y las propias finanzas. } \\
\text { - Acciones de lectura y escritura funcional, y conocimiento numérico. } \\
\text { medio ambiente. } \\
\text { - Examen de salud. } \\
\text { - Apoyo a la toma de medicación. } \\
\text { - Adaptación de jornada y horario. } \\
\text { - Transpones físicas y arquitectónicas. } \\
\text { - Entidades de previsión social voluntaria. }\end{array}$ \\
\hline Bienestar emocional & $\begin{array}{l}\text { - Acciones para el fomento de la autoestima y la autovaloración, aceptación e inclusión en el } \\
\text { centro. } \\
\text { - Charlas de desarrollo (usuarios y usuarias, y sus familias/tutores). } \\
\text { - Intervenciones de ajuste psicosocial. } \\
\text { - Intervenciones conductuales. } \\
\text { - Medición del grado de satisfacción. }\end{array}$ \\
\hline Desarrollo laboral & $\begin{array}{l}\text { - Acciones de orientación laboral. } \\
\text { - Realización de la actividad laboral. } \\
\text { - Evaluación del desempeño de puestos y tareas. } \\
\text { - Formación en competencias básicas laborales. } \\
\text { - Formación en seguridad laboral. } \\
\text { - Promoción. } \\
\text { - Paso al empleo. } \\
\text { - Acciones de formación y adiestramiento en tareas específicas. } \\
\text { - Acciones de adaptación del puesto de trabajo: } \\
\text { - Productos de apoyo. } \\
\text { - Programa Ergohobe Banaka. } \\
\text { - Pcciones para el conocimiento y la integración en la organización: } \\
\text { - Visitas a otros centros. } \\
\text { - Visitas a clientes. }\end{array}$ \\
\hline
\end{tabular}

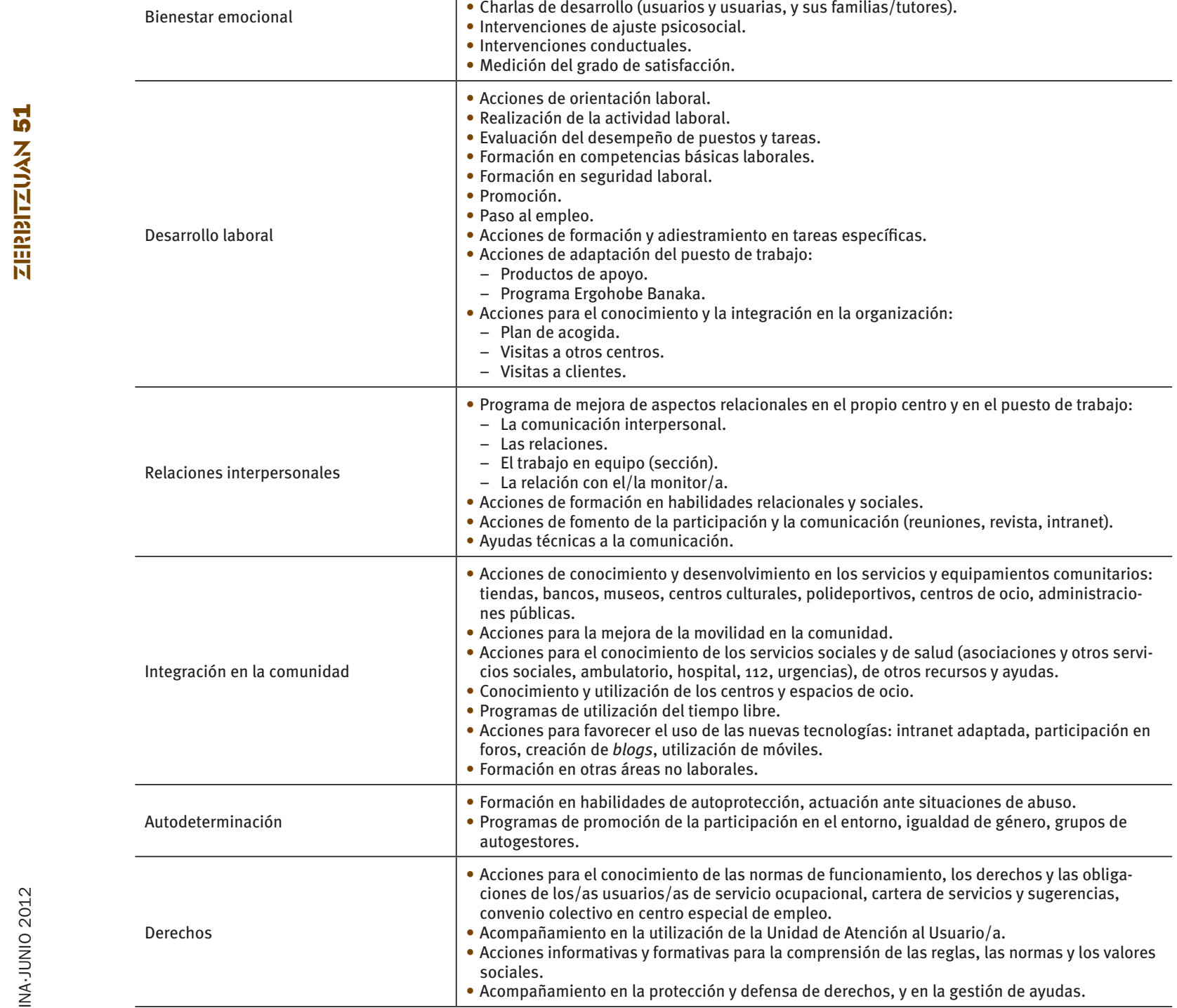

Fuente: Elaboración propia, a partir de American Association on Mental Retardation (1997: 131). 
7. Herramienta y protocolo para la detección del deterioro/envejecimiento, la articulación de perfiles de necesidad de apoyo y el establecimiento de programas de apoyo

Este apartado recoge una primera propuesta para desarrollar una herramienta y un protocolo adaptados para la detección del deterioro/envejecimiento, la articulación de perfiles de necesidad de apoyo y el establecimiento de programas de apoyo, según el Método de perfiles de adecuación de la tarea a la persona (Badiola et al., 2011) y el Modelo de apoyos individuales... (Elorriaga et al., 2010) de Lantegi Batuak. Su validación definitiva requiere un proceso de pilotaje, de acuerdo al esquema que aquí se expone. La aplicación de la herramienta/protocolo, así como la de los programas de apoyo para perfiles con necesidades suplementarias de apoyo, estará supeditada al futuro desarrollo de este apartado.

En ese proceso se contemplan las siguientes fases:

1. Articulación de un protocolo que facilite la detección del deterioro/envejecimiento, de acuerdo con el siguiente planteamiento:

- Se han analizado las variables del perfil (Badiola et al., 2011) y se han clasificado en tres tipos, según su importancia en la detección del deterioro/envejecimiento.

- Se han definido otras variables, obtenidas en el curso de este estudio: cansancio, memoria, irritabilidad y cambios de humor, tristeza y apatía, y aislamiento. Estas variables, que se relacionan con determinadas variables del perfil, serán tenidas en cuenta más adelante.

- Para validar la propuesta, se plantea llevar a cabo un pilotaje utilizando las variables críticas y las otras variables mencionadas. La muestra que se seleccionará deberá contemplar personas con discapacidad intelectual con deterioro por envejecimiento, o por otros motivos, y se hará un contraste con personas que no presenten deterioro.

- Una vez obtenidos los resultados, se validará la selección de estas variables críticas y se establecerá la puntuación que se considerará necesaria para que se active el protocolo o la 'señal de alarma' por deterioro/ envejecimiento.

2. Articulación de perfiles de necesidades de apoyo para toda la población con necesidades suplementarias de apoyo (discapacidad intelectual, trastorno mental y trastorno del comportamiento):

- Según las necesidades, se distinguen tres perfiles de apoyo: alto, medio y bajo (cfr. Cuadro 4).

- Estos nuevos perfiles se definirían a partir de:

- Las valoraciones del método de perfiles (variables críticas, de media y de baja intensidad).
- Las valoraciones de las otras variables citadas anteriormente.

- Otros aspectos que ya se conocen: ayuda de terceras personas, adaptación de horarios, doble diagnóstico, presencia de problemas de conducta o intervenciones en el ámbito de la de salud (u otros), examen de salud.

3. Establecimiento de programas de apoyo para estos perfiles:

- Se establecerían actividades, espacios, recursos y ratios de atención, entre otros elementos.

- Los programas de apoyo intensivo podrían ser de intensidad alta, media y básica (cfr. Cuadro 4).

Cuadro 4. Articulación entre perfiles de necesidades de apoyo y programas de apoyo

\begin{tabular}{l|l|l}
\hline $\begin{array}{l}\text { Perfil de } \\
\text { necesidad } \\
\text { de apoyo }\end{array}$ & $\begin{array}{l}\text { Niveles de dedicación a actividades } \\
\text { laborales y no laborales }\end{array}$ & $\begin{array}{l}\text { Programas } \\
\text { de apoyo }\end{array}$ \\
\hline Alto & $\begin{array}{l}\text { Dedicación del } 50 \% \text { o menos a } \\
\text { actividades laborales, y del 50\% 0 } \\
\text { más a actividades no laborales }\end{array}$ & $\begin{array}{l}\text { Intensidad } \\
\text { alta }\end{array}$ \\
\hline Medio & $\begin{array}{l}\text { Dedicación de entre el } 50 \% \text { y el } 75 \% \\
\text { a actividades laborales, y de entre } \\
\text { el } 25 \% \text { y el } 50 \% \text { a actividades no } \\
\text { laborales }\end{array}$ & $\begin{array}{l}\text { Intensidad } \\
\text { media }\end{array}$ \\
\hline Bajo & $\begin{array}{l}\text { Similar al modelo actual de servicio } \\
\text { ocupacional o centro especial de } \\
\text { empleo, que pivota en función del } \\
\text { plan de apoyos individuales }\end{array}$ & $\begin{array}{l}\text { Intensidad } \\
\text { baja }\end{array}$ \\
\hline
\end{tabular}

Fuente: Elaboración propia.

\section{Prioridades estratégicas y objetivos}

A la luz de las conclusiones del estudio, analizados los retos y las necesidades que la situación de deterioro/envejecimiento plantea, $y$ desde la perspectiva de construir la visión de Lantegi Batuak explicitada en el epígrafe 5 , el conjunto de propuestas de actuación, soluciones y dispositivos habrán de articularse en el marco de dos prioridades estratégicas:

1. Adecuar, en el seno de Lantegi Batuak, y en función de la diversidad de las necesidades de las personas con discapacidad intelectual que envejecen o sufren deterioros significativos, la oferta y diversidad de apoyos de carácter suplementario que puedan necesitar, con la asignación de medios y recursos adecuados.

2. Proponer a las administraciones públicas competentes, de manera directa o a través de las organizaciones representativas en las que Lantegi Batuak participa, un nuevo sistema de empleo, ocupación y apoyos capaz de dar una respuesta efectiva y no discriminatoria a las necesidades evolutivas de las personas con discapacidad intelectual que envejecen o sufren deterioros significativos. 


\section{Propuestas de actuación, soluciones, dispositivos}

Con el objeto de responder a las prioridades estratégicas y objetivos recogidos en el epígrafe anterior, se plantean las siguientes propuestas de actuación, soluciones y dispositivos, relacionados con la organización de Lantegi Batuak, con las administraciones públicas y con el movimiento asociativo.

Cuadro 5. Propuestas dirigidas a los grupos de interés de Lantegi Batuak

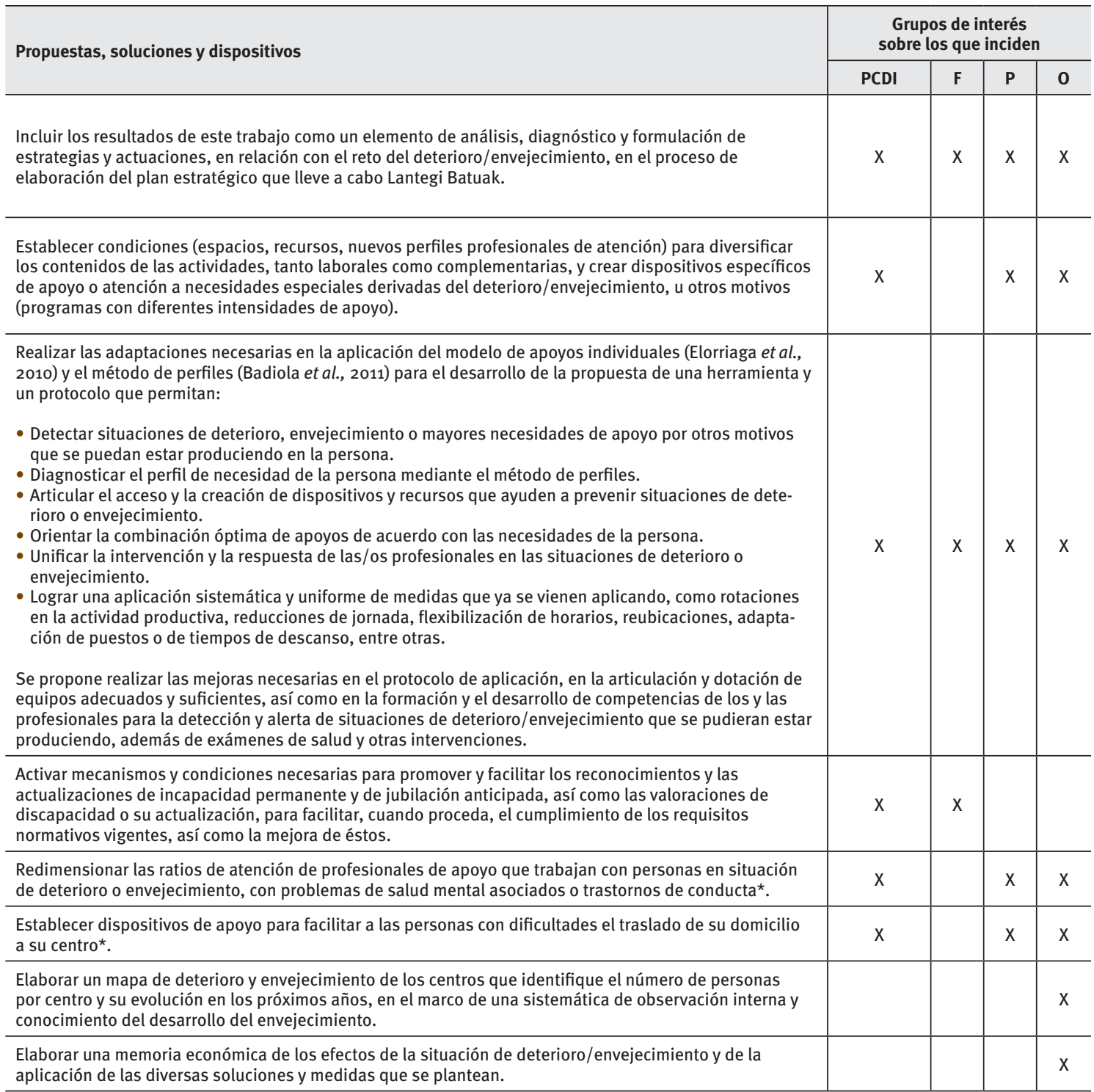

PCDI: personas con discapacidad intelectual. F: familiares. P: profesionales de apoyo de Lantegi Batuak. O: Lantegi Batuak como organización. * Propuesta condicionada a la obtención de financiación suficiente.

Fuente: Elaboración propia. 


\begin{tabular}{|c|c|c|c|c|}
\hline \multirow{2}{*}{ Propuestas, soluciones y dispositivos } & \multicolumn{4}{|c|}{ Administraciones públicas destinatarias } \\
\hline & AGE & GV & DFB & EE.LL. \\
\hline $\begin{array}{l}\text { Reivindicar que se lleven a cabo las modificaciones normativas que permitan los escenarios y } \\
\text { las combinaciones de alternativas de apoyo a la actividad laboral y ocupacional, flexibilizando } \\
\text { las condiciones de acceso y la movilidad entre recursos y ayudas, garantizando siempre que } \\
\text { la persona mantenga el nivel de ingresos de, como mínimo, la renta de garantía de ingresos. } \\
\text { Esta reclamación se refiere, en particular, a compatibilizar un régimen de incapacidad } \\
\text { permanente, total o parcial, con una actividad laboral en centro especial de empleo o con una } \\
\text { actividad en servicio ocupacional, en un régimen de mayor intensidad de apoyos para las } \\
\text { personas con discapacidad intelectual. }\end{array}$ & $x$ & $x$ & $x$ & \\
\hline $\begin{array}{l}\text { Proponer la articulación de dispositivos de valoración técnica para dictaminar capacidades y } \\
\text { la posibilidad de acceso a los diversos recursos, escenarios y combinaciones, en condiciones } \\
\text { de igualdad para todas las personas. }\end{array}$ & $x$ & $x$ & $x$ & \\
\hline $\begin{array}{l}\text { Contribuir a reivindicar el desarrollo de un sistema unificado de valoración y reconocimiento } \\
\text { de la discapacidad y la dependencia que esté al servicio de las personas y contemple, entre } \\
\text { otras, las especificidades de las necesidades de apoyo de las personas con discapacidad } \\
\text { intelectual, y que, entre otras cuestiones: } \\
\text { - Permita la toma en consideración de dictámenes de los servicios médicos y psicológicos de } \\
\text { los centros especiales de empleo y servicios ocupacionales. } \\
\text { - Elimine trabas burocráticas innecesarias. } \\
\text { - Permita contar con herramientas comunes y validadas de valoración y diagnóstico. }\end{array}$ & $\mathrm{x}$ & $x$ & $x$ & \\
\hline $\begin{array}{l}\text { Instar a la aplicación de los convenios para la gestión de servicios prevista en el art. } 69 \text { de } \\
\text { la Ley } 12 / 2008 \text { de Servicios Sociales, cómo fórmula jurídica de apoyo de la Administración } \\
\text { a los programas con diferentes intensidades de apoyo en servicio ocupacional, de acuerdo } \\
\text { con lo que se plantea en la propuesta que recoge este documento, en cuanto supuesto de } \\
\text { singularidad de la actividad y carácter innovador y experimental. }\end{array}$ & & & $\mathrm{X}$ & \\
\hline $\begin{array}{l}\text { Reivindicar la financiación estable y suficiente para redimensionar los ratios de atención } \\
\text { de profesionales de apoyo en los casos en que trabajen con personas con necesidades } \\
\text { suplementarias. }\end{array}$ & & $x$ & $\mathrm{x}$ & \\
\hline $\begin{array}{l}\text { Reivindicar que se garantice la financiación estable y suficiente para contar con equipos } \\
\text { multidisciplinares (unidades de apoyo) en centro especial de empleo, en número suficiente, } \\
\text { para atender las necesidades específicas de apoyo de sus trabajadoras/es. }\end{array}$ & $x$ & $x$ & & \\
\hline $\begin{array}{l}\text { Reivindicar que se garantice la financiación estable y suficiente para contar con preparadores } \\
\text { laborales y equipos profesionales adecuados y suficientes en la modalidad de empleo } \\
\text { con apoyo, para evitar y prevenir el deterioro/envejecimiento entre trabajadores de esta } \\
\text { modalidad. }\end{array}$ & $x$ & $x$ & & \\
\hline $\begin{array}{l}\text { Reivindicar la financiación estable y suficiente para desarrollar el pilotaje de las herramientas } \\
\text { y el protocolo para la detección del deterioro/envejecimiento; la articulación de perfiles de } \\
\text { necesidad de apoyo y el establecimiento de programas de apoyo, así como para el diseño y } \\
\text { aplicación de programas con diferentes intensidades de apoyo. }\end{array}$ & & $x$ & $\mathrm{x}$ & \\
\hline $\begin{array}{l}\text { Instar el apoyo al transporte (individual o grupal) para el traslado de las personas que lo } \\
\text { requieran de su domicilio al centro especial de empleo o servicio ocupacional. }\end{array}$ & & $\mathrm{x}$ & $\mathrm{x}$ & \\
\hline $\begin{array}{l}\text { Contribuir a la reivindicación del movimiento asociativo de que se intensifiquen los servicios } \\
\text { de apoyo a las familias (servicios de apoyo a familias, residenciales, de ocio, respiro) y } \\
\text { conseguir una mayor intensidad de los servicios de apoyo y promoción de la autonomía } \\
\text { personal. }\end{array}$ & & $x$ & $X$ & $x$ \\
\hline $\begin{array}{l}\text { Apoyar la reivindicación de cambios normativos en materia de jubilación, para favorecer una } \\
\text { respuesta global y adecuada, que contemple en su conjunto la realidad y las necesidades } \\
\text { de las personas con discapacidad, dirigida a asegurar una pensión digna, suficiente y justa } \\
\text { (reducción razonable de los tiempos y tipos de cotización, condiciones y requisitos de } \\
\text { diagnóstico y grado de discapacidad). }\end{array}$ & $x$ & & & \\
\hline $\begin{array}{l}\text { Instar la mejora de bases, criterios y fuentes de información sobre datos cuantitativos de } \\
\text { la población con discapacidad, en particular, la población con discapacidad intelectual en } \\
\text { situación de envejecimiento o deterioro. }\end{array}$ & & $x$ & $x$ & \\
\hline
\end{tabular}

AGE: Administración General del Estado. GV: Gobierno Vasco. DFB: Diputación Foral de Bizkaia. EE.LL.: entidades locales. Fuente: Elaboración propia.

\section{Cuadro 7. Propuestas que Lantegi Batuak plantea desarrollar en cooperación con el conjunto del movimiento asociativo de la discapacidad}

Fomentar la colaboración con el conjunto del movimiento asociativo para reivindicar las propuestas expuestas dirigidas a las administraciones públicas.

Promover que el movimiento asociativo intensifique los servicios de apoyo para las personas y familias en la información y la formación sobre cómo afrontar el deterioro/envejecimiento, la preparación para la etapa de jubilación, el relevo, la pérdida de familiares u otras situaciones en las que la persona con discapacidad pasa a ejercer nuevas funciones de cuidador/a de sus familiares.

Desarrollar una planificación de los recursos necesarios (centros de día, residencias, viviendas, tutela) que la evolución de las necesidades de las personas con discapacidad intelectual va a requerir en los próximos años, para exigir a las administraciones públicas una dotación de plazas y recursos adecuados y suficientes.

Fuente: Elaboración propia. 
AMERICAN ASSOCIATION ON MENTAL RETARDATION (1997): Retraso mental: definición, clasificación y sistemas de apoyo, Madrid, Alianza.

AGUADO, A. L. et al. (2007) Necesidades de las personas con discapacidad intelectual en proceso de envejecimiento, Bilbao, Diputación Foral de Bizkaia [khttp://www.bizkaia.net/Homez/ Archivos/DPTO3/Temas/Pdf/topaketa16/ Publicacion $\% 20$ Discapacidad\%20y\%20 Envejecimiento.pdf〉]

BADIOLA, V. et al. (2011): Método de perfiles de adecuación de la tarea a la persona, Loiu, Lantegi Batuak, $3^{\underline{a}}$ ed. revisada [<http://www.lantegi. com/wp-content/uploads/downloads/oo_ Publicaciones/manuales/Metodo\%20 perfiles_3ed.pdf $>$.

DIPUTACIÓN FORAL DE BIZKAIA (2010): Plan para la Participación y Calidad de Vida de las Personas con Discapacidad en Bizkaia 2010-2013, Bilbao, Diputación Foral de Bizkaia [<http://www. bizkaia.net/home2/Archivos/DPTO3/Noticias/ Adjuntos/Plan\%20Discapacidad_cas\%202010. pdf>].

ELORRIAGA, E. et al. (dirs.) [2011]: Investigación sobre el envejecimiento y deterioro de las personas con discapacidad intelectual en el ámbito ocupacional y del empleo en Bizkaia, Loiu, Lantegi Batuak [<http://www.lantegi.com/ wp-content/uploads/downloads/2012/04/ LANTEGIBATUAK_Estudio-Envejecimiento.pdf)].
FEAPS (2005): Cartera de servicios sociales del movimiento FEAPS, Madrid, FEAPS [resumen ejecutivo disponible en <http://www.feaps.org/ profesionales/documentos/servicios_resumen. pdf)].

FEAPS NAVARRA (2005): Envejecimiento y deterioro de las personas con discapacidad intelectual en el ámbito del empleo en la Comunidad Foral de Navarra, Pamplona, Fundación Koine-Aequalitas [<http://www.navarra.es/ NR/rdonlyres/DDC9A5A5-32Ao-4C2E-BF7C6C7EAE4DD329/63795/EnvejecimientoEmpleo. pdf $>$.

INSTITUTO NACIONAL DE ESTADÍSTICA (2008): Encuesta de Discapacidad, Autonomía Personal y Situaciones de Dependencia 2008, Madrid, Instituto Nacional de Estadística [<http://www.ine.es/jaxi/ menu.do?type $=$ pcaxis $\&$ path $=\% 2 \mathrm{Ft}_{15} /$ p418\&file $=$ inebase $\& L=0$ > $]$.

JEFATURA DEL ESTADO (2003): “Ley 51/2003, de 2 de diciembre, de Igualdad de Oportunidades, No Discriminación y Accesibilidad Universal de las Personas con Discapacidad", Boletín Oficial del Estado, no 289, 3-12-2003, sección I, págs. 43.187-43.195 [<http://www.boe.es/diario_ boe/txt.php?id=BOE-A-2003-22066)].

MONTERO, D. et al. (2006): Estudio de la incidencia de problemáticas asociadas en personas con discapacidad intelectual en Lantegi Batuak, Lantegi Batuak [<http://www.lantegi.com/ wp-content/uploads/downloads/oo_ Publicaciones/estudios/Estudio_discapacidad_ intelectual_LB.pdf`].

NACIONES UNIDAS (2006): Convención sobre los Derechos de las Personas con Discapacidad y Protocolo Facultativo, Nueva York, Naciones Unidas 
[<http://www.un.org/disabilities/documents/ convention/convoptprot-s.pdf〉].

NOVELL. R. et al. (2008): Informe Séneca. Envejecimiento y discapacidad intelectual en Cataluña 20002008, Federación Catalana Pro-personas con Discapacidad Intelectual [disponible resumen ejecutivo en 〈http://www.dincat.cat/ fichero-21051_21051〉].

PRESIDENCIA DEL GOBIERNO VASCO (2000): “Ley 10/2000, de 27 de diciembre, de Carta de Derechos
Sociales", Boletín Oficial del País Vasco, no 249, 30-12-2000, págs. 23.377-23.379 [ http://www.euskadi.net/cgi-bin_k54/ bopv_20?c\&f=20001230\&a=200005881)].

- (1998): “Ley 12/1998, de 22 de mayo, contra la Exclusión Social”, Boletín Oficial del País Vasco, n- 105, 8-6-1998, págs. 10.46710.506 [ [http://www.euskadi.net/cgibin_k54/bopv_20?c\&f=19980608 $\& a=199802519>$ ]. 